\title{
Soluble Mainchain Polyoxadiazoles as Electron Transport Materials
}

\author{
Matthias PATZ, Masayuki TAKAHASHI, and Kohei GoTo ${ }^{\dagger}$ \\ Tsukuba Research Laboratories, JSR Corporation \\ 25 Miyukigaoka, Tsukuba, Ibaraki 305-0841, Japan
}

(Received January 14, 2000)

KEY WORDS Soluble Poly(oxadiazole)/ Electron Transport / Light Emission Diode / Fluorescence /

In recent years much progress has been made toward the development of polymer based Light Emission Diodes (LEDs). ${ }^{1,2}$ For such LEDs polymers are required that are either selective hole or electron conductor. Mainchain polyoxadiazoles have been proposed as electron transport materials, ${ }^{3-8}$ but often suffer from low solubility in organic solvent. We therefore started to study polyoxadiazoles containing an indane ring in the backbone. The indane ring is bulky and leads to a twisting of the structure. Both factors are well known to increase the solubility of polymers. The polymers are obtained by reaction of 1,1,3-trimethyl-3-phenylindane4',5-dicarboxylic acid 1 with aromatic hydrazides 2 under acidic conditions similar to those described by Ueda et al. (Figure 1). 9,10

Mulder et al. reported a polyoxadiazole obtained by condensation of $\mathbf{1}$ with hydrazine for gas separation membranes. ${ }^{11,12}$ That polymer has much smaller $\pi$ systems and shows therefore not sufficient electron affinity and electron mobility for application as electron transport material. Polymers with the structure shown in Figure 1 are to the best of our knowledge new.

\section{EXPERIMENTAL}

\section{Materials and Apparatus}

Polymers were characterized by glass transition temperature $T_{\mathrm{g}}$ (using DuPont 2000), the temperature of 5\% weight loss $T_{\mathrm{d} 5}$ (using Seiko SCC-5200, heating rate 10 ${ }^{\circ} \mathrm{C}$ min ${ }^{-1}$ under nitrogen), ${ }^{1} \mathrm{H}$ NMR spectroscopy (using JEOL JNM-EX-90), IR-spectroscopy (using JEOL JIR5500), fluorescence spectroscopy (of polymer films using JASCO F 5-777) and inherent viscosity $\eta_{\text {inh }}$ (at $30^{\circ} \mathrm{C}, 50$ $\mathrm{mg} \mathrm{mL} \mathrm{m}^{-1}$ in $97 \% \mathrm{H}_{2} \mathrm{SO}_{4}$ ). All starting materials are commercially available. With the exception of the methane- sulfonic acid, they were used as received. Methanesulfonic acid was distilled under reduced pressure and stored under argon.

Semi-empirical calculations of the repeating unit were made with MOPAC 6.0 using AM1 hamiltonians. ${ }^{13}$ Only ground-state calculations have been performed.

Typical Procedure for the Preparation of Polyoxadiazoles

$3 \mathrm{~g}$ Phosphorus pentoxide were dissolved at $100^{\circ} \mathrm{C}$ in $20 \mathrm{~mL}$ of a mixture of methanesulfonic acid and methanesulfonic acid anhydride (about $1: 1$ weight ratio) under argon. The temperature was lowered to $70^{\circ} \mathrm{C}, 1.59 \mathrm{~g}$ $(8.20 \mathrm{mmol})$ terephthalic dihydrazide $\mathbf{2 b}$ and $2.66 \mathrm{~g}(8.20$ mmol) 1,1,3-trimethyl-3-phenylindane-4,,5-dicarboxylic acid 1 were added and the mixture stirred for $3 \mathrm{~h}$ at 70 ${ }^{\circ} \mathrm{C}$. The resulting viscous solution was poured into about $200 \mathrm{~mL}$ ice/water and the obtained polymer washed with water, aqueous $\mathrm{NaHCO}_{3}$, water and methanol and dried under reduced pressure, yielding $3.3 \mathrm{~g}(90 \%)$ of a slightly yellow polymer $\mathbf{3 b}$ with an inherent viscosity of 0.64 $\mathrm{dL}^{-1}$. Samples used for evaluation in LEDs have been redissolved in tetrachloroethane and precipitated in methanol.

\section{LED Fabrication}

LEDs have been prepared by first spincasting of the sulfonium precursor polymer of poly(phenylene vinylene) (precursor PPV, $50 \mathrm{~nm}$ thickness) onto cleaned indium tin oxide (ITO) coated glass, thermal conversion of the polymer to PPV according to a published procedure ${ }^{14}$ followed by casting the polyoxadiazole $(50 \mathrm{~nm}$ thickness) and evaporation of aluminum on top. The LEDs have not been encapsulated and been operated under air.

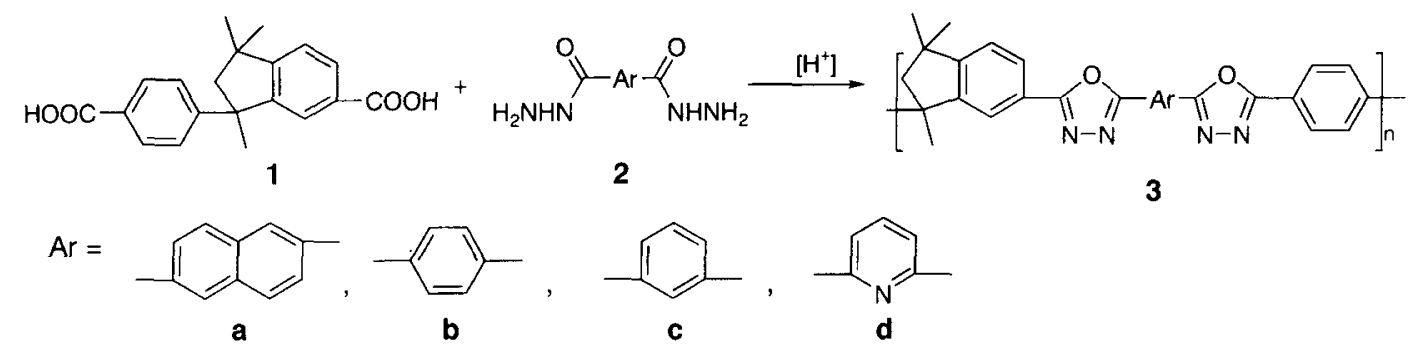

Figure 1. Preparation of polyoxadiazoles.

\footnotetext{
${ }^{\dagger}$ To whom correspondence should be addressed
} 


\section{RESULTS AND DISCUSSION}

The procedure for the one step polymerization of hydrazides with acids in a mixture of methanesulfonic acid and phosphorous pentoxide reported by Ueda ${ }^{9,10}$ has been modified. We found that the addition of methanesulfonic anhydride allows to reduce reaction time and temperature. Shorter reaction time and lower temperature should help to avoid possible degradation reactions during the polymerization, that would lead to inferior, darkened polymers. Consequently, our polymers were usually almost colorless. Complete cyclization from the intermediate polyhydrazide to the polyoxadiazole was confirmed by IR spectroscopy (absence of bands due to the hydrazide group at 3250 and $1650 \mathrm{~cm}^{-1}$ ) and TGA (no weight loss below $300^{\circ} \mathrm{C}$ ).

The polymers show glass transition temperatures $T_{\mathrm{g}}$ of more than $300^{\circ} \mathrm{C}$ and high decomposition temperatures $T_{\mathrm{d} 5}$ of more than $440^{\circ} \mathrm{C}$ (Table I), as expected for polyoxadiazoles. The thermal properties do not depend significantly on the type of aromatic group $\mathrm{Ar}$ in the backbone. Selfstanding films can been prepared that exhibit blue fluorescence. With the exception of the naphthalene containing polymer, all polymers are soluble in organic solvents such as $N$-methylpyrrolidone (NMP), chloroform or tetrachloroethane. The solubility reflects the stiffness of the polymer backbone. The $m$-linkage in the $m$-phenylene and 2,6-pyridine polymer 3c and 3d leads to a twisting of the backbone and therefore a much better solubility than the corresponding $p$-phenylene polymer 3b. The large aromatic system of the naphthalene polymer $\mathbf{3 a}$ is reducing the solubility so far, that the polymer is no longer soluble in the tested organic solvents.

Table I. Properties of homopolymers 3a-d

\begin{tabular}{cccccccc}
\hline Polymer & $T_{\mathrm{g}} /{ }^{\circ} \mathrm{C}$ & $T_{\mathrm{d} 5} /{ }^{\circ} \mathrm{C}$ & $\eta / \mathrm{dL} \mathrm{g}^{-1}$ & $\lambda_{\mathrm{f}} / \mathrm{nm}^{\mathrm{a}}$ & $\mathrm{NMP}^{\mathrm{b}} \mathrm{CHCl}_{3}{ }^{\mathrm{b}} \mathrm{C}_{2} \mathrm{H}_{2} \mathrm{Cl}_{4}{ }^{\mathrm{b}}$ \\
\hline 3a & 353 & 456 & 0.37 & 436 & - & - & o \\
3b & 336 & 443 & 0.64 & 418 & $\circ$ & - & + \\
3c & 318 & 459 & 1.11 & 380 & + & + & + \\
3d & 332 & 442 & 0.39 & 383 & + & + & + \\
\hline
\end{tabular}

${ }^{\mathrm{a}}$ Fluorescence maximum, upon excitation at $250 \mathrm{~nm} .{ }^{\mathrm{b}}+:>$ $5 \%$ soluble, o: partial soluble, - : insoluble.
The fluorescence emission of the $m$-phenylene and 2,6pyridine polymer 3c and 3d (about $380 \mathrm{~nm}$ ) polymers are at significantly smaller wavelength than that of the p-phenylene polymer $3 \mathbf{b}(418 \mathrm{~nm})$ due to the higher resonance stabilization of the latter. The naphthalene polymer 3a shows an even higher emission wavelength (436 $\mathrm{nm}$ ) due to the increase of the size of the $\pi$-system. The emission is in this case almost completely in the visible region.

Copolymers have been prepared by reaction of the acid 1 with two types of hydrazides $(\mathbf{2 a -} \mathbf{d})$, as well as with hydrazides and hydrazine. For example, the reaction of 1 with naphthalene-2,6,-dicarboxylic acid dihydrazide $2 \mathbf{a}$ and hydrazine (molar ratio: $1: 0.5: 0.5$ ) yields a polymer that shows similar optical and thermal properties as the homopolymer 3a, but significantly improved solubility. This copolymer is readily soluble in NMP, chloroform and tetrachloroethane, whereas the homopolymer is only partially soluble in tetrachloroethane and insoluble in NMP and chloroform (first entry in Table I).

Further development of such polymers would be much faster, if the properties of the polymers would be "predictable". Semi-empirical calculations are an easy and

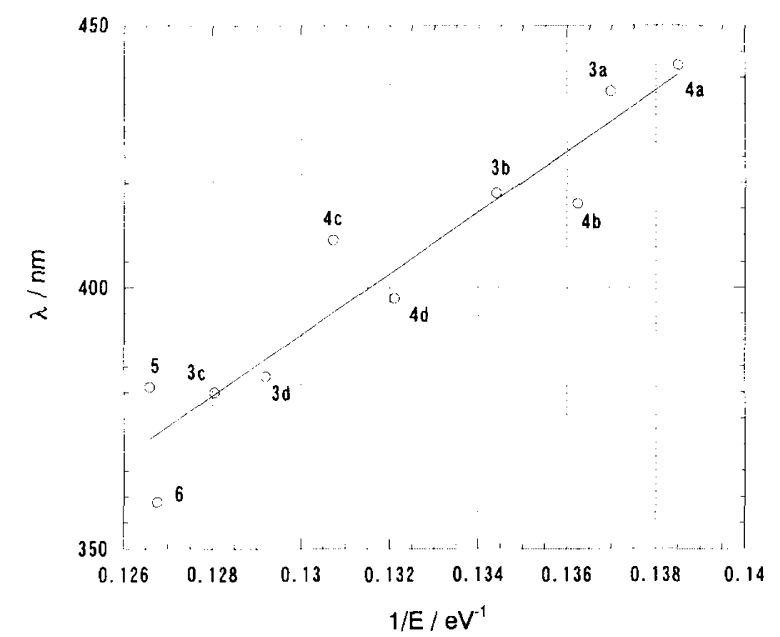

Figure 2. Correlation between fluorescence wavelength $\lambda$ and calculated inverse HOMO-LUMO gap $1 / E(\lambda=5831 / E-367, r=$ 0.948; for labels see Figure 3).
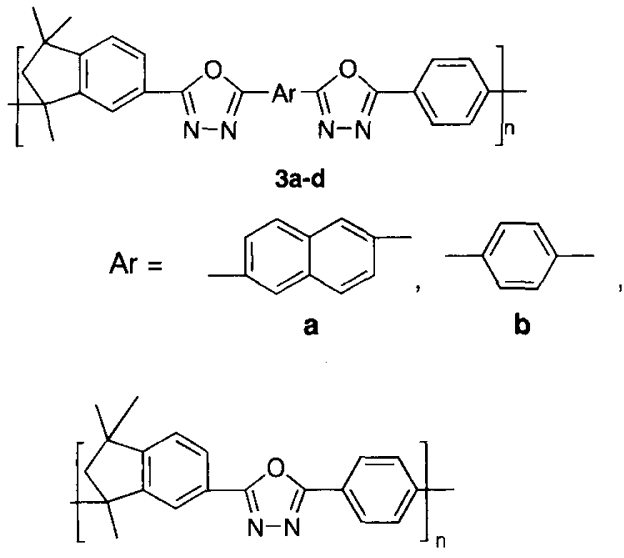

5<smiles>CC(C)(C)Oc1ccc(-c2nnc([Al]c3nnc(-c4ccc(C(C)(C)C)cc4)o3)o2)cc1</smiles><smiles>Cc1cccc(C)c1</smiles>

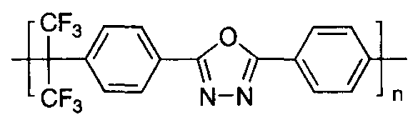

6

Figure 3. Polymers studied by fluorescence spectroscopy. 
fast tool to achieve such predictions. The geometry of the oxadiazole ring is known to be calculated systematically inaccurate $\left(\mathrm{N}-\mathrm{N}\right.$ bond too short, $\mathrm{C}-\mathrm{N}$ two long) ${ }^{15}$ using AM1 and other semi-empirical parameter sets such as PM3 and MNDO, however, such systematic effects should cancel out if correlation between experimental and calculated values are used for "normalization". For the calculation of frontier orbitals it was sufficient to calculate only the repeating unit, since these orbitals are dominated by $\pi$ states and the indane ring is interrupting the $\pi$-conjugation along the back bone. In order to broaden the data set, we also prepared polyoxadiazoles containing ether and hexafluoroisopopylidene units in the back-bone (structures shown Figure 3). A plot of the fluorescence emission wavelength versus the inverse value of the calculated HOMO-LUMO gap yields indeed a reasonable linear correlation (Figure 2). A similar linear correlation (Figure 4) has been found between the calculated and experimental LUMO energy of oxadiazoles $^{16,17}$ and polyoxadiazoles ${ }^{18}$ (Figure 5). Experimental values taken from the literature ${ }^{16-18}$ are based on electrochemical measurements. The LUMO energy level is

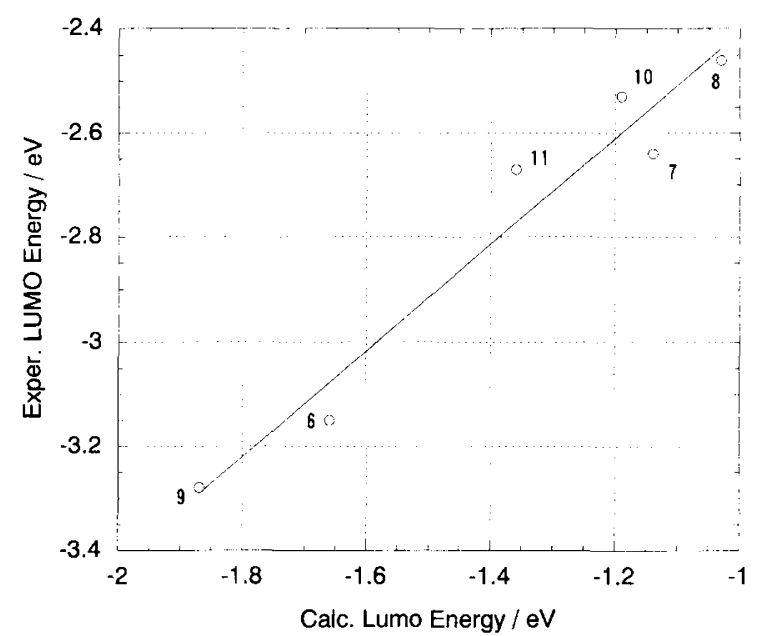

Figure 4. Plot of experimental vs. calculated LUMO energy for a variety of oxadiazoles and polyoxadiazoles $\left(\operatorname{Exp}=1.01^{*}\right.$ Calc $1.39, r=0.974$, experimental data from ref $16-18$ ).

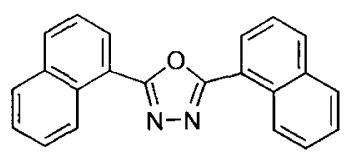

7
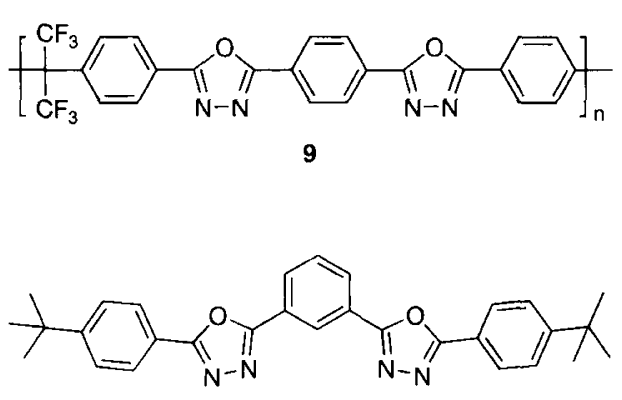

10

an important factor for the ease of electron injection from the cathode into electron transporting material, and is therefore significantly influencing the driving voltage of the LED. For the application of polymer LEDs, a low driving voltage is a vital requirement.

Although not very accurate, correlation such as those shown in Figures 2 and 4 can be used as an easy and fast guidance for the optimization of the electronic properties of polyoxadiazoles.

Preliminary tests as electron transport materials have been made with bilayer LEDs using poly(phenylene vinylene) (PPV) as hole transport material, indium tin oxide (ITO) coated glass as transparent anode and aluminum as cathode. In such an LED holes are injected from the ITO into the PPV, and electrons from the aluminum into the polyoxadiazole. Holes and electrons combine at the polymer-polymer interface under emission of light. In our case the visible green emission is derived from the PPV. Using $\mathbf{3 b}$ as electron transport material a maximum luminance of about $200 \mathrm{~cd} \mathrm{~m}^{-2}$ at $29 \mathrm{~V}$ with a maximum efficiency of $0.3 \mathrm{~cd} \mathrm{~A}^{-1}$ (at $18 \mathrm{~cd} \mathrm{~m}^{-2}$ ) was achieved (Figure 6), compared to values below $5 \mathrm{~cd} \mathrm{~m}^{-2}$

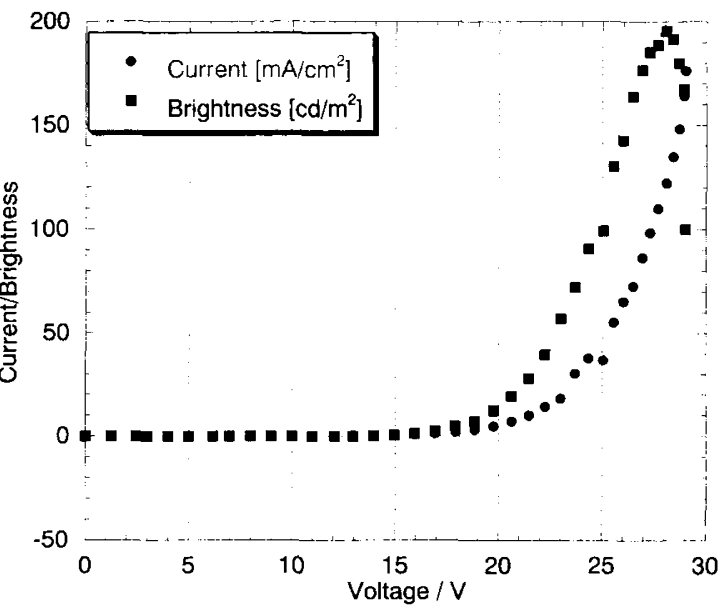

Figure 6. Typical example for the current-voltage and brightness/voltage of an LED based on $\mathbf{3 b}$ [ITO/PPV $(50 \mathrm{~nm}) / 3 \mathbf{b}(50 \mathrm{~nm}) /$ Al].

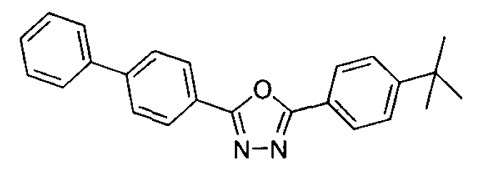

8

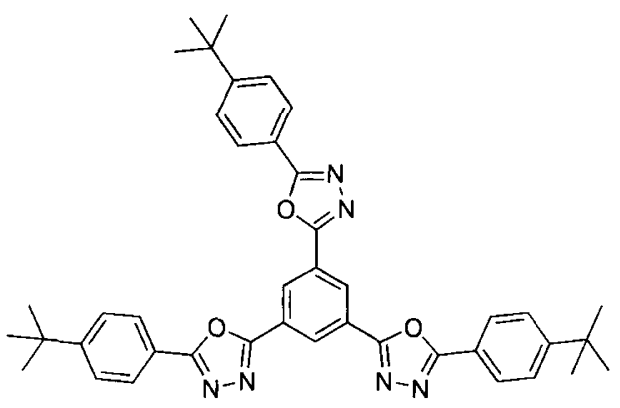

11

Figure 5. Structure of oxzdiazoles with experimentally determined LUMO energy. ${ }^{16^{-18}}$ 
for the maximum luminance and $10^{-2}-10^{-3} \mathrm{~cd} \mathrm{~A}^{-1}$ for maximum efficiency typically obtained without an electron transport layer.

The new soluble polyoxadiazoles are obviously good candidates as electron transporting materials in polymer LEDs.

Acknowledgment. We would like to thank Prof. Dr. H. Sato, Mrs. N. Nakao, and Mr. I. Shiroishi of Tokyo University of Agriculture and Technology for help with the evaluation of the polymers in LEDs.

\section{REFERENCES AND NOTES}

1. A. Kraft, A. C. Grimsdale, and A. B. Holmes, Angew. Chem. Int. Ed., 37, 402 (1998).

2. C. H. Chen, J. Shi, and C. W. Tang, Macromol. Symp., 125, 1 (1997).

3. J. Kido, G. Harada, and K. Nagai, Chem. Lett., 161 (1996).

4. M. Strukelj, F. Papadimitrakopolous, T. M. Miller, and L. J. Rothberg, Science, 267, 1969 (1995).

5. Q. Pei and Y. Yang, Chem. Mater., 7, 1568 (1995).

6. R. Brütting, P. Pösch, and P. Strohriegel, Macromol. Chem.
Phys., 198, 2743 (1997)

7. X.-C. Li, A. C. Grimsdale, A. B. Holmes, S. C. Moratti, T. M. Yong, J. Grüner, and R. H. Friend, Photonic and Optoelectronic Polymers, 322 (1997).

8. Z. Peng, Z. Bao, and M. E. Galvin, Adv. Mater., 10, 680 (1998).

9. M. Ueda and H. Sugita, J. Polym. Sci., Part A, Polym. Chem. Ed., 26, 159 (1988).

10. M. Ueda and M. Oda, Polym. J., 21, 193 (1989).

11. E. R. Hensema, M. E. R. Sena, M. H. V. Mulder, and C. A. Smolders, J. Polym. Sci., Part A, Polym. Chem. Ed., 32, 527 (1994).

12. E. R. Hensema, M. E. R. Sena, M. H. V. Mulder, and C. A. Smolders, Gas. Sep. Purif., 8, 149 (1994).

13. M. J. S. Dewar, E. G. Zoebisch, E. F. Healy, and J. J. P. Stewart, J.Am. Chem. Soc., 107, 3902 (1985).

14. P. L. Burn, D. D. C. Bradley, R. H. Friend, D. A. Halliday, A. B. Holmes, R. W. Jackson, and A. Kraft, J. Chem. Soc., Perkin Trans. 1, 3225 (1992).

15. G. Brocks and A. Tol, J. Chem. Phys., 106, 6418 (1997).

16. C.-C. Wu, J. C. Sturm, R. A. Register, J. Tian, E. O. Dana, and M. E. Thomson, IEEE Trans. Elec. Dev., 44, 1269 (1997).

17. J. Bettenhausen, PhD Thesis, University of Bayreuth, 1996.

18. X.-C. Li, A. B. Holmes, A. Kraft, S. C. Moratti, G. C. W. Spencer, F. Calcialli, J. Grüner, and R. H. Friend, J. Chem. Soc., Chem. Comm., 2211 (1995). 